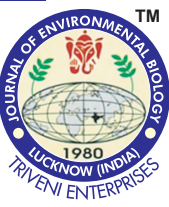

\title{
Characteristics of water vapor flux of riverside wetland ecosystem in cold regions and its influence analysis
}

\section{Authors Info \\ F. Wang ${ }^{1,2,3}$, D. Ma', H. Zhao ${ }^{1,2 *}$, M. Sun ${ }^{1}$ and X. Yan ${ }^{1}$ \\ ${ }^{1}$ North China University of Water Resources and Electric Power, Henan Province, 450046, P.R. China \\ ${ }^{2}$ Collaborative Innovation Center of Water Resources Efficient Utilization and Support Engineering, Henan Province, 450046, P.R. China \\ ${ }^{3}$ Henan Key Laboratory of Water Environment Simulation and Treatment, Henan Province, 450046, P.R. China \\ *Corresponding Author Email : zhaoheng@ncwu.edu.cn \\ Edited by \\ Prof. Ahmed Jalal Khan Chowdhury \\ Reviewed by \\ Dr. Yiping Li \\ Dr. Ming Dou}

\begin{abstract}
Aim: The aim of this study was to provide some scientific reference for the protection and restoration of the riverside wetland ecosystem in the cold regions.

Methodology: The study was based on the measurement data of Eddy Covariance observation experiment, to research the variations of water vapor flux over daily and seasonal scales of ecosystem in experimental area, and the factors affecting water vapor flux.

Results: This study showed that the diurnal changes of water vapor flux were in a single-peak type, the maximum values appeared between12:00-15:00 hr. On a seasonal scale, the highest value appeared in summer and lowest appeared in winter, and the daily accumulated value of water vapor flux in the growing season was 2.83 times higher than the non-growing season.
\end{abstract}

Interpretation: The water vapor flux was mainly affected by vapor pressure difference, air temperature and radiation, among which radiation had the greatest influence on water vapor flux.

Keywords : Air temperature, Radiation, Vapor pressure difference, Water vapor flux, Wetland ecosystem
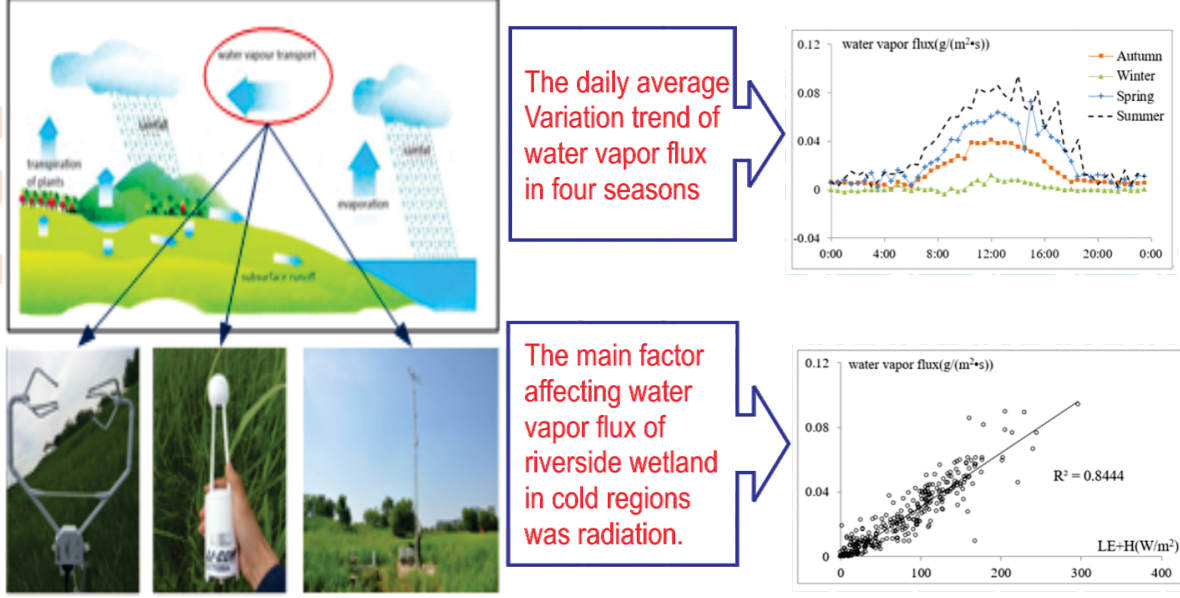

Citation: Wang, F., D. Ma, H. Zhao, M. Sun and X. Yan: Characteristics of water vapor flux of riverside wetland ecosystem in cold regions and its influence analysis. J. Environ. Biol., 40, 584-555 (2019). 


\section{Introduction}

Continuous observation of water vapor flux of ecosystem can reflect the changes of hydrology and climate in a region (Baldocchi et al., 1996; Shukla et al., 1982; Howlader et al., 2018). Water vapor flux is an important parameter of water cycle process in ecological system, and is an indicator for the evaluation of vegetation water status, moreover, it is an important factor affecting energy balance and a major part of water balance(Irmak et al., 2011; Li et al., 2006; Shu et al., 2016). Water vapor flux of wetland is an important mode for water and heat exchange between wetland and atmosphere, including underlying surface evaporation, vegetation transpiration and turbulent flow of water vapor in atmosphere. Researchers at home and abroad have carried out studies from different aspects on the change rules and their influencing factors of water vapor flux in wetland ecosystem
(Yong et al.,2017; El-Aziz, 2018). Studies on marsh wetland have demonstrated that interannual variation of water vapor flux is caused by temperature influence on ecosystem; and water vapor flux of marsh wetland is mainly affected by net radiation (Goulden, 2007; Sun, 2008; Dhami et al., 2018). Further, observation on water vapor flux of peatland found that daily and seasonal variations were in single peak curves, and variation was mainly affected by both the radiation and vapor pressure difference (Peng, 2007; Khan, 2018). Currently a lot of research has been carried out on water vapor flux in wetland ecosystem, but not much on riverside wetland ecosystem in cold regions. Considering this situation, a typical riverside wetland in cold regions-Harbin Jinhe Bay Wetland of Heilongjiang Province was selected as study area. Based on the data measured in Eddy Covariance observation test, the variation of water vapor flux on ecosystem days and seasonal scale in the test area as well as its

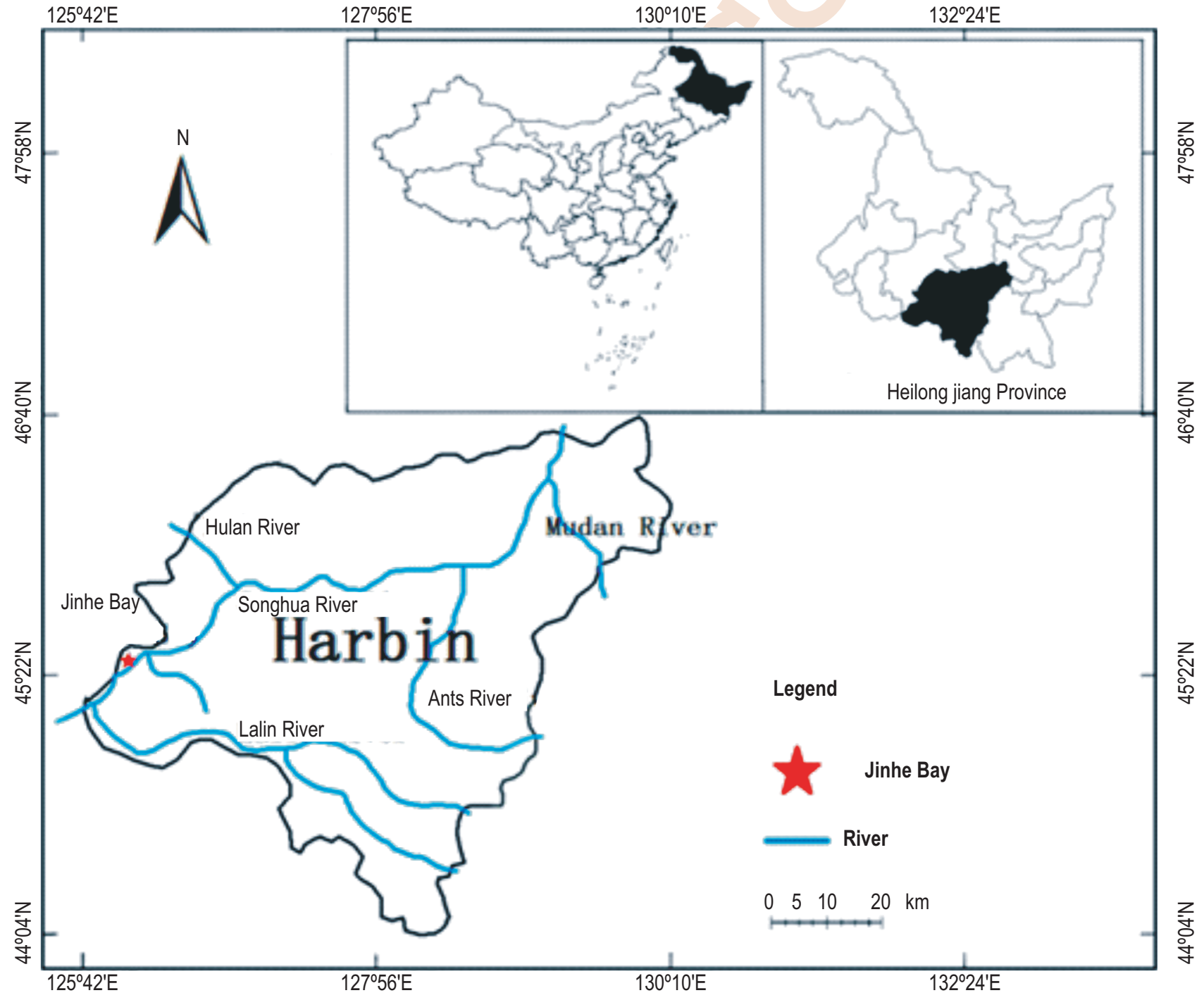

Fig. 1 : Location map of Jinhe Bay Wetland. 
influencing factors were studied systematically, aiming to provide reference for the protection and restoration of wetland water ecosystem in cold regions.

\section{Materials and Methods}

Jinhe Bay Wetland is located on the west bank of Harbin City, Heilongjiang Province, geographic coordinates is $45^{\circ} 4635^{\prime \prime}-$ $45^{\circ} 46^{\prime} 58^{\prime \prime} \mathrm{N}, 126^{\circ} 29^{\prime} 07^{\prime \prime}-126^{\circ} 29^{\prime} 45^{\prime \prime} \mathrm{E}$. The arc-shapewetland with water on three sides, covers a total area of $1.8 \mathrm{~km}^{2}$, and it is a riverside wetland in high floodplain area (Fig. 1) (Lin et al., 2015; Shabi et al., 2018). The area enjoys a semi-humid continental monsoon climate, and it has four distinctive seasons with longer winter and shorter summer. Annual average sunshine duration is $2636.3 \mathrm{hr}$, annual average temperature is $3.2^{\circ} \mathrm{C}$, average annual rainfall is $569.1 \mathrm{~mm}$. Influenced by the southeast ocean, from June to September is $341.5 \mathrm{~mm}$, with more heavy rain in July and August, and average water surface evaporation is $796.3 \mathrm{~mm}$. Reeds, sedges and poplars are dominant vegetation in the area. The Jinhe Bay Wetland plays an important role in the regional microclimate regulation, preventing soil erosion and protecting the ecological environment in the coastal zone of Songhua River.

Experimental observation system: The observation system mainly composed of open circuit infrared $\mathrm{CO}_{2} / \mathrm{H}_{2} \mathrm{O}$ analyzer ( $\mathrm{LI}-$ 7500, LI-COR, Inc., Lincoln, Nebraska, USA), three-dimensional ultrasonic anemometer (CSAT3, Campbell, Scientific, USA) and data collector (CR3000 Campbell, Scientific, USA). The infrared $\mathrm{CO}_{2} / \mathrm{H}_{2} \mathrm{O}$ analyzer and three-dimensional ultrasonic anemometer, mounted on an arm about $0.5 \mathrm{~m}$ long, were fixed on the top of at ower, and towards the prevailing trend throughout the year, so as to reduce the influence of air disturbance on the instrument. The data collector could collect raw data of $10 \mathrm{~Hz}$ in real time and obtain the flux data and other covariance data by online calculation of Logger Net software and record them in a PC card. A set of air humidity sensor, rainfall observation system, and evaporation observation system was set up under the framework of Eddy Covariance System to receive online flux data for half an hour every month through the software of Peanut Shell, VSPM virtual serial port, and LoggerNet4.0, at the same time on the instrument for routine supervision and maintenance, read the memory card $10 \mathrm{~Hz}$ flux and rainfall and other data every two months. In this research, the open-path Eddy Covariance System installed $10 \mathrm{~m}$ above the ground, and the plants within $1000 \mathrm{~m}$ of the system were mainly reeds, sporadic distribution of the tower head, poplar, larch and other vegetation, data observation was done from 00:00, August 1, 2015 to 00:00, August 1, 2016.

Data processing: In actual observation, the land surface is often not an ideal horizontal uniform state, but has a complex topography, coupled with the flux tower and the instrument in the installation process is inevitable slight tilt, the measured data there will be some errors. In the paper, TR (triple coordinate rotation) method was used to check Eddy Covariance flux data of Jinhe Bay Wetland.
There would be outliers or data missing inevitably due to the disturbance of environmental factors, internal factors and external factors on instrument. In order to reduce the impact of these data on the research results, the outliers should be removed. Daytime missing data would be interpolated with MDV method, night missing data with nonlinear regression method, short time missing data or abnormal data with linear interpolation method (Xu et al., 2009; Falge et al., 2001; Khattak et al., 2018).

\section{Results and Discussion}

Interdiurnal dynamic characteristic: From August 2015 to July 2016, most water vapor flux was positive (Fig. 2), showing that water vapor flux of the ecological system was mainly transferred from the surface to the atmosphere, the trend of daily change of water vapor flux was consistent in spring, summer and autumn, and water vapor flux at night fluctuated in the vicinity of 0 , showing that vegetation and soil evaporation was weak at that time. Water vapor flux began to rise from 6:00 to 8:00 hr in the morning and reached the highest value of day from 12:00 to $15: 00 \mathrm{hr}$, then decreased to about 0 again from 18:00 to 20:00 hr. In winter, especially in January and February, water vapor flux fluctuation was around 0 , showing vegetation transpiration and soil evaporation were weak in winter. In February the rising time of water vapor flux was $1.5 \mathrm{hr}$ later than that of the other 3 seasons.

The mean water vapor flux of the whole year was $2.05 \times 10^{-2} \mathrm{~g} /\left(\mathrm{m}^{2} \mathrm{~s}\right)$. Daytime peak value of water vapor flux was in the following order: summer >spring >autumn>winter. Daily mean water vapor flux in the 4 seasons was: autumn $1.58 \times 10^{-2} \mathrm{~g} /\left(\mathrm{m}^{2} \mathrm{~s}\right)$, winter $0.18 \times 10^{-2} \mathrm{~g} /\left(\mathrm{m}^{2} \mathrm{~s}\right)$, spring $2.61 \times 10^{-2} \mathrm{~g} /\left(\mathrm{m}^{2} \mathrm{~s}\right)$, summer $3.70 \times 10^{-2} \mathrm{~g} /\left(\mathrm{m}^{2} \mathrm{~s}\right)$. The active period moisture exchange in wetland ecosystems lasts for the longest in summer, about 6:00 19:30, while the period was slightly shorter in spring and autumn, about 7:00 - 19:00.

Daily changes of water vapor flux of Jinhe Bay Wetland under typical weather conditions in different seasons are shown in Fig. 3. In summer, change regulation of water vapor flux in sunny days was similar to that of interdiurnal changes of monthly mean value, showing a single peak: 6:00 - 14:00 was the rising stage, 14:00 - 18:00 was the declining stage, and water vapor flux at night was 0 . In winter, water vapor flux in sunny days was around 0 , no obvious change. Meanwhile, it is found that changes of water vapor flux in rainy days had no rules, which was related to the weather of the day before and after the typical day. On August $28^{\text {th }}$, it began to rain at noon time, so the changes at wee hours and in the morning were consistent with sunny days; June 10th was a typical day among the continuous rainfall days, so water vapor flux showed greater volatility from early morning.

Seasonal dynamic characteristic: Annual variation of water vapor flux (Fig. 4) showed that there were obvious seasonal differences of water vapor flux. Generally, high in summer and low 


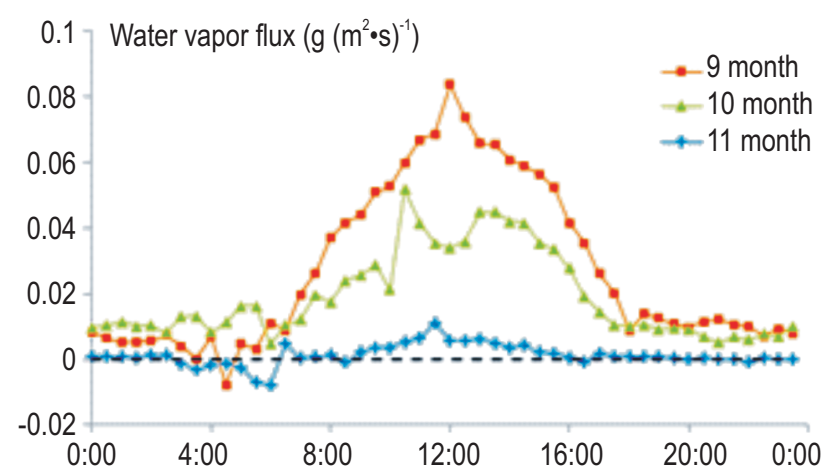

(a) Autumn

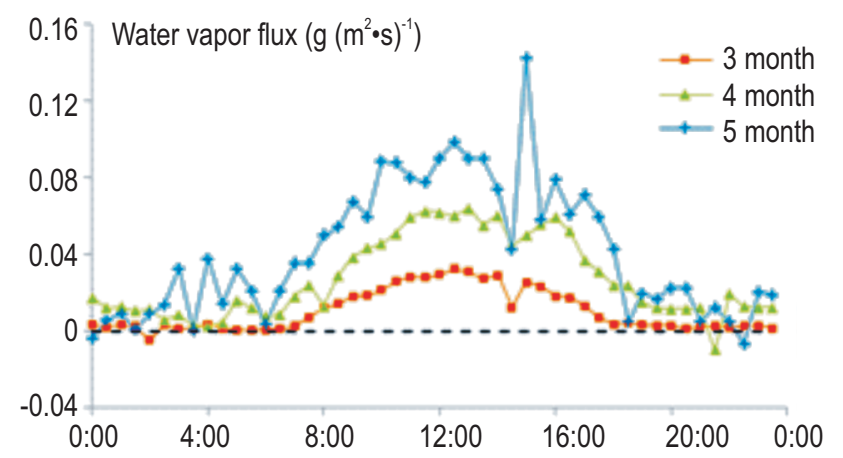

(a) Spring

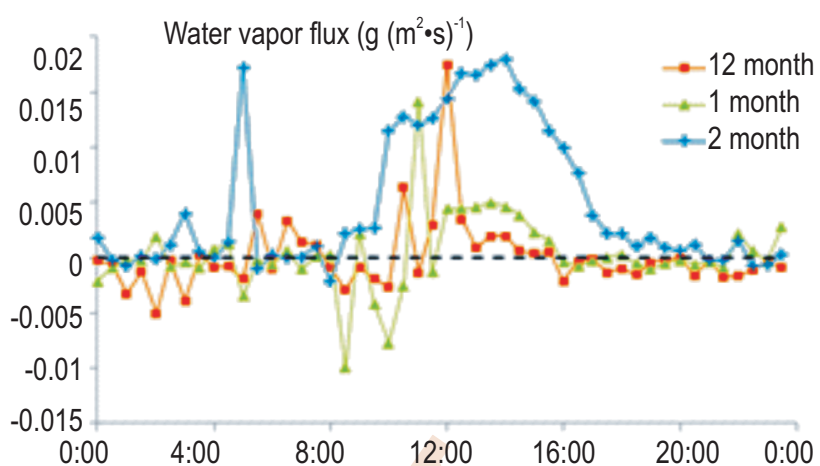

(b) Winter

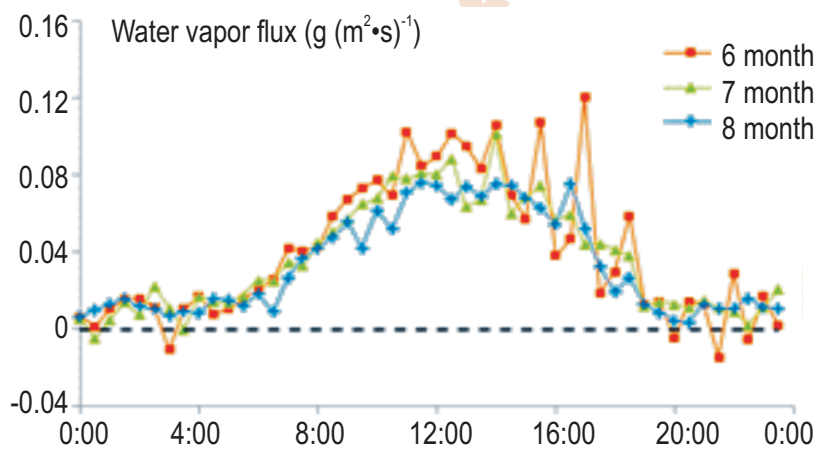

(b) Summer

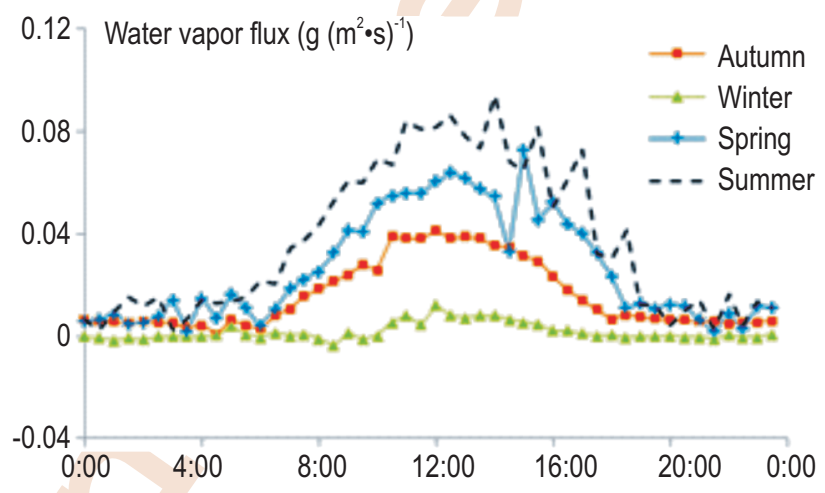

(e) Average of four seasons

Fig. 2 : Average daily variation of water vapor flux.

in winter. Daily cumulative average value of water vapor flux in the year was $0.98 \mathrm{~g} /\left(\mathrm{m}^{2} \mathrm{~s}\right)$, the maximum value was $6.21 \mathrm{~g} /\left(\mathrm{m}^{2} \mathrm{~s}\right)$, the minimum value was $-2.06 \mathrm{~g} /\left(\mathrm{m}^{2} \mathrm{~s}\right)$, the highest monthly average value was June $2.07 \mathrm{~g} /\left(\mathrm{m}^{2} \mathrm{~s}\right)$, the lowest was December0.01g/( $\left.\mathrm{m}^{2} \mathrm{~s}\right)$. Water vapor flux decreased in autumn due to less rainfall and solar radiation; in winter, rainfall free and vegetation frozen, water vapor flux was near 0 ; in spring, water vapor flux increased with the increase of solar radiation; in summer, water vapor flux reached its peak in the year along with the increase of temperature and rainfall.
In growing season (May- September), water vapor flux fluctuated greatly, peaks and troughs occurred alternatively. The cumulative value of water vapor flux was 2.83 times the value in non-growing season (October-April).

Effect of VPD on water vapor flux of wetland: Studies have shown that water vapor flux and VPD (vapor pressure difference) have a certain quadratic curve relationship: water vapor flux first increases with the increase of VPD, then decreases with increase of VPD, as shown in Fig. 5 (Wang, 2011; Madugundu et al., 2017). 


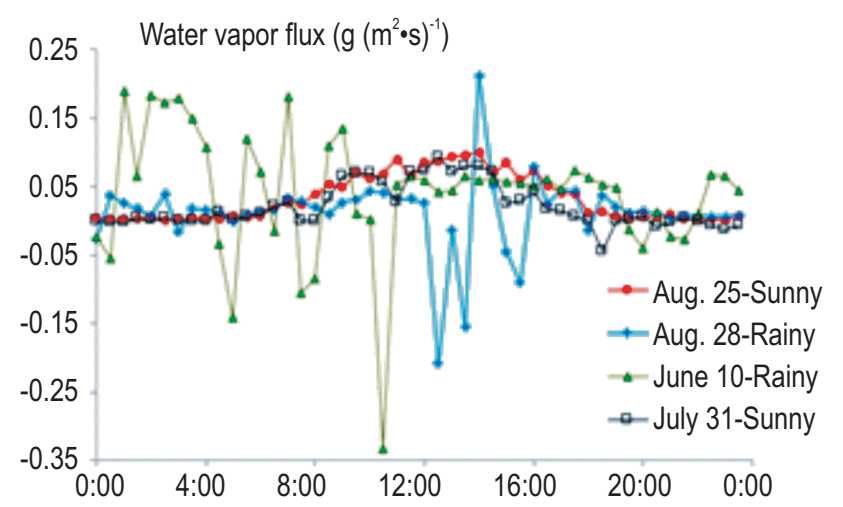

(a) Typical Summer day

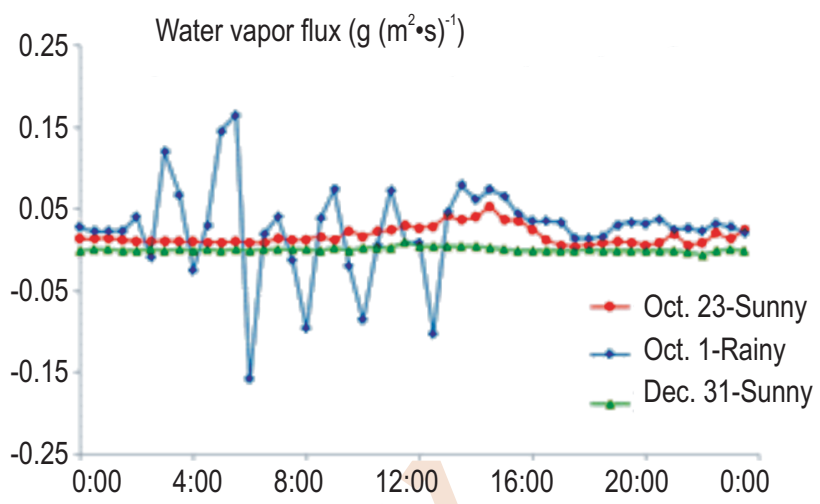

(b) Typical Winter day

Fig. 3 : Daily variation of water vapor flux under different weather conditions in different seasons.

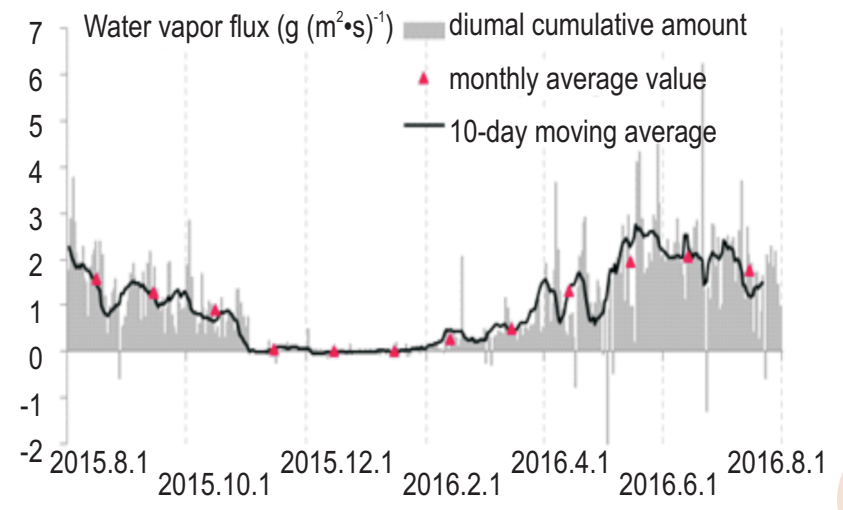

Fig. 4 : Annual variation trend of water vapor flux.

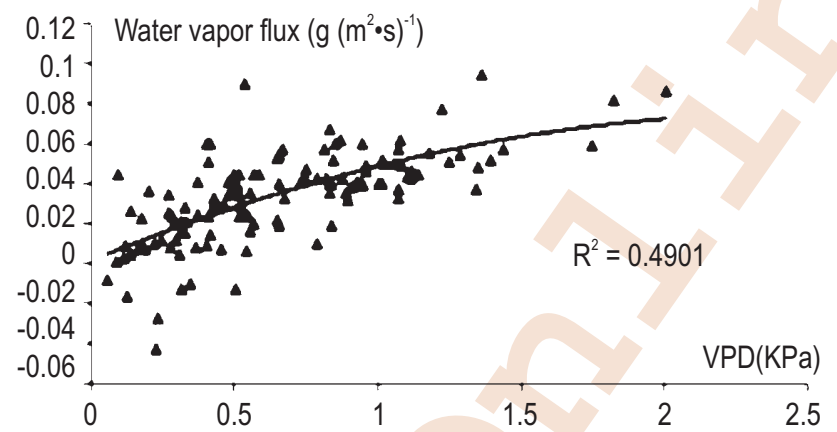

(a) growing season

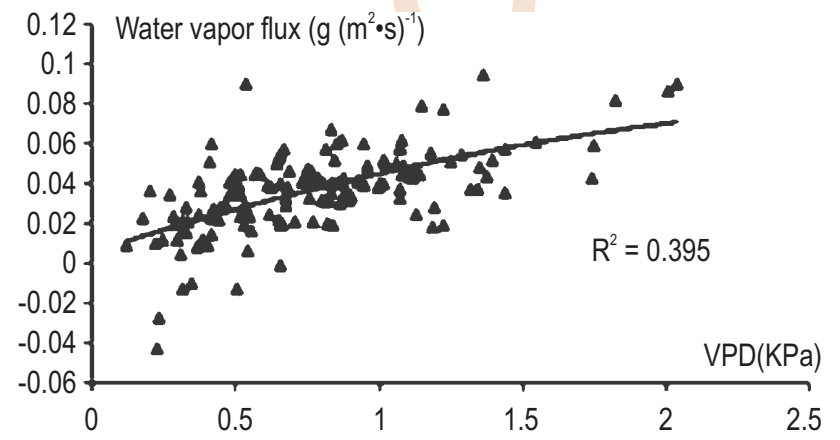

(a) rainfall

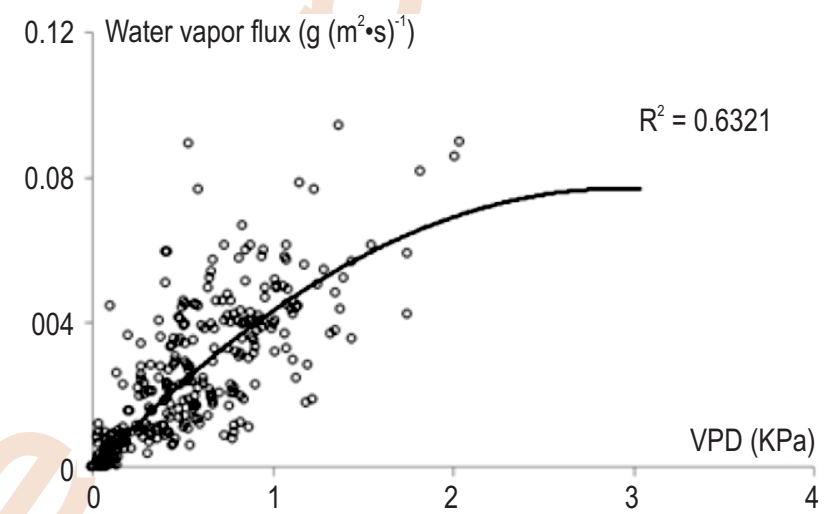

Fig. 5 : Relationship between water vapor flux and VPD.

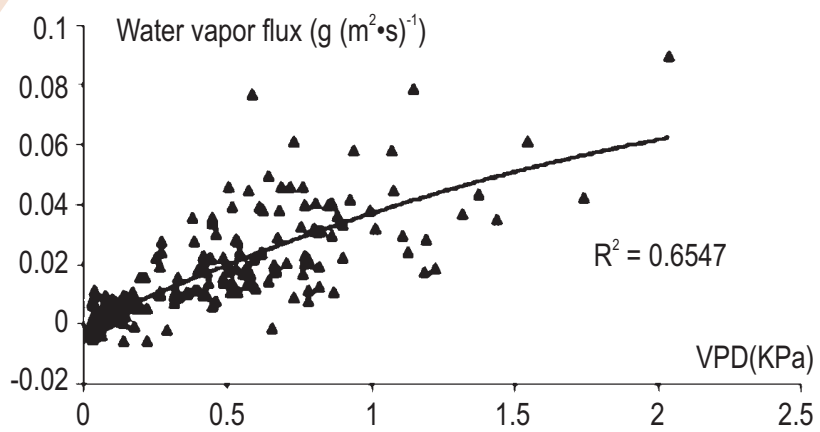

(b) non growing season

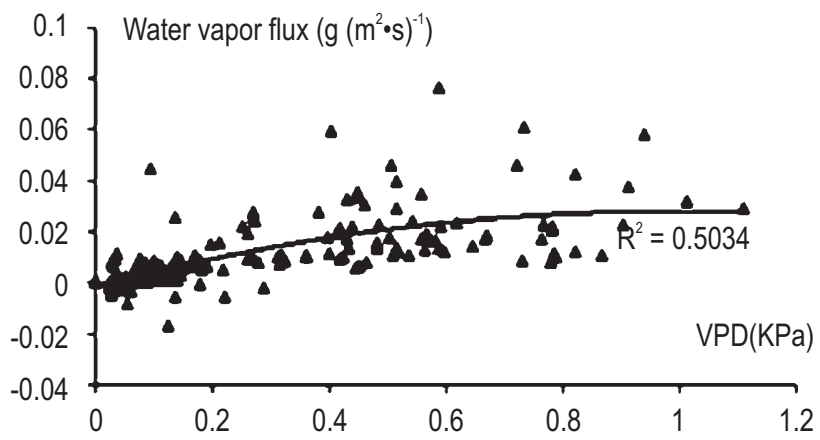

(b) non rainfall

Fig. 6 : Relationship between water vapor flux and VPD under different conditions. 


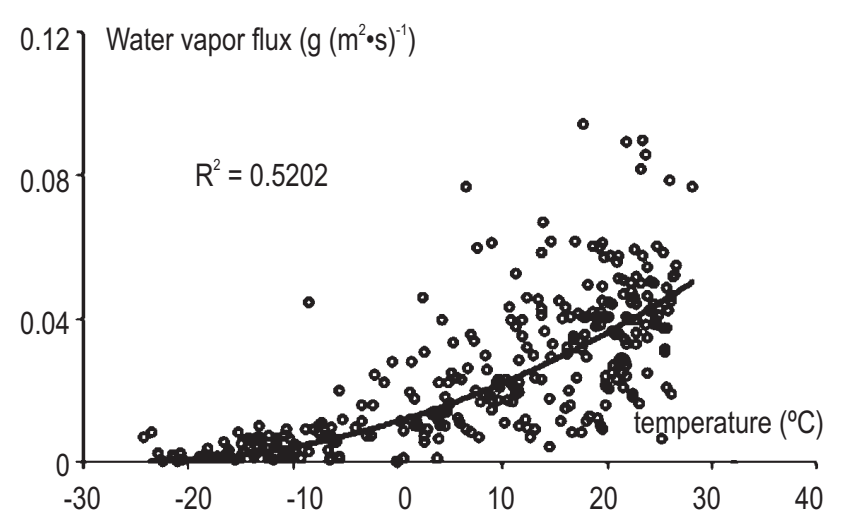

Fig. 7 : Relationship between water vapor flux and air temperature.

VPD can represent the relationship between air drying degree and transpiration, the drier the air is, the more conducive to vegetation transpiration. But when the drying degree exceeds a certain threshold, vegetation stomatal will close. To a certain extent, this can prevent the transpiration of vegetation, thus affecting the variation of water vapor flux. Research on the changes of VPD in the year showed that the maximum value of VPD was less than 2.5KPa under the meteorological conditions in the test area. The fitting curve showed (Fig. 6) that the inflection point of $\mathrm{VPD}$ value was about $3 \mathrm{KPa}$. Thus, it can be known that no VPD exceeded the threshold in the test area.

Effect of temperature on water vapor flux of wetland: The rise of temperature can promote water vaporization, affecting the transfer of water vapor. In addition, temperature change also affects atmospheric pressure and other environmental factors, indirectly effects water vapor transfer (Zhang et al., 2015; Meiresonne et al., 2003). It can be seen from Fig. 7 that water vapor flux increased with temperature increase. The test area witnessed significant changes of temperature in the year. When the temperature was less than $0^{\circ} \mathrm{C}$, water vapor flux increased little with temperature increase; as the temperature continued to rise above zero, water vapor flux increased exponentially.

Effects of radiation on water vapor flux of wetland: The water vapor flux and radiation are positively correlated, the water vapor increased with the increase of $\mathrm{LE}+\mathrm{H}$ (latent heat flux and sensible heat flux), and the correlation coefficient between two was high, as shown in Fig. 9. Fig.10 (a) shows that interdiurnal variation trend of water vapor flux and radiation was consistent on sunny days, but downtrend of water vapor flux lagged the radiation change in the afternoon. Fig. 10 (b) shows that both water vapor

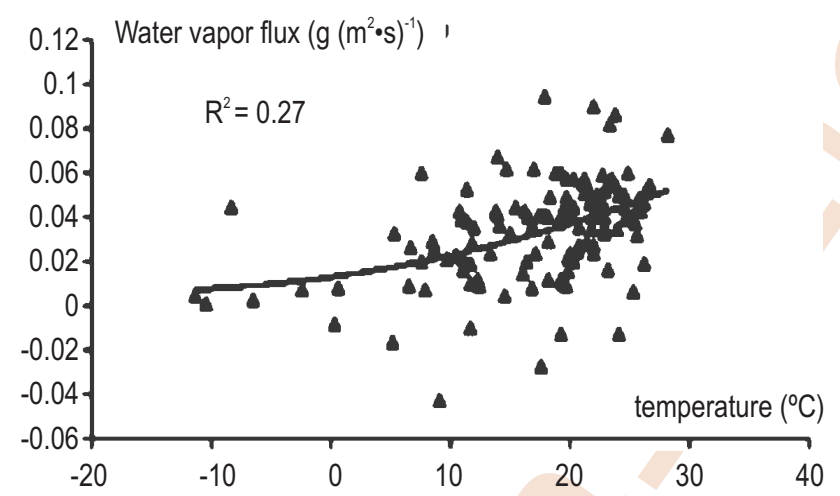

(a) rainfall

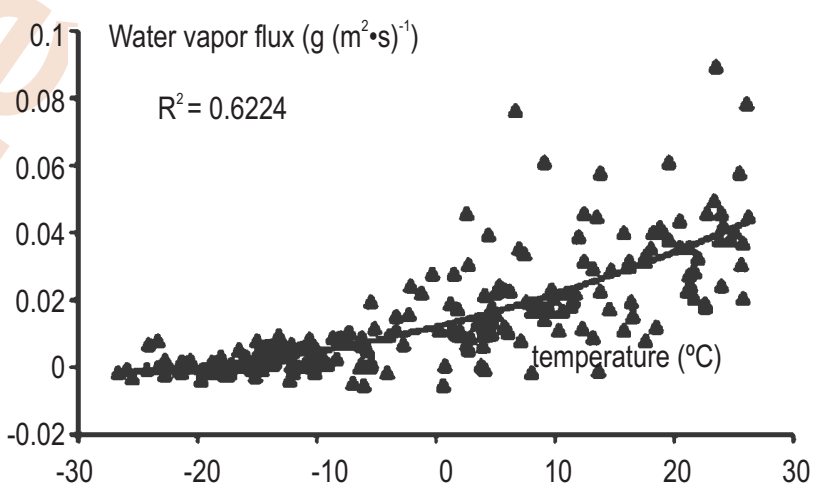

(b) non rainfall

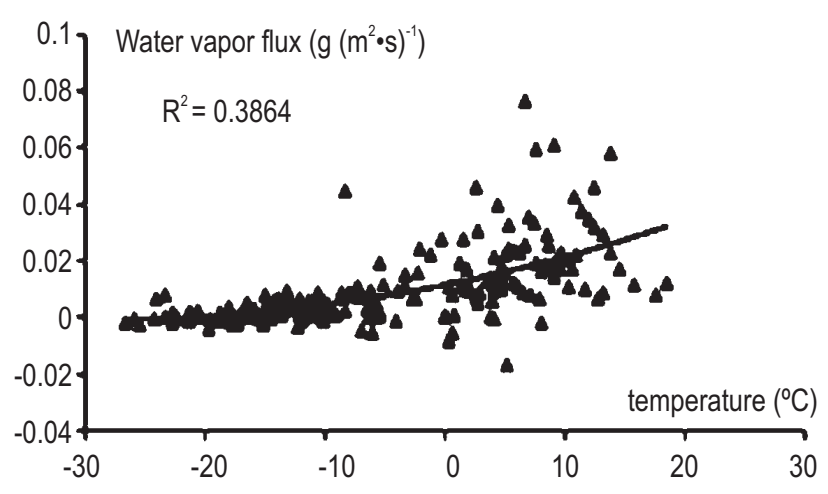

(b) non growing season

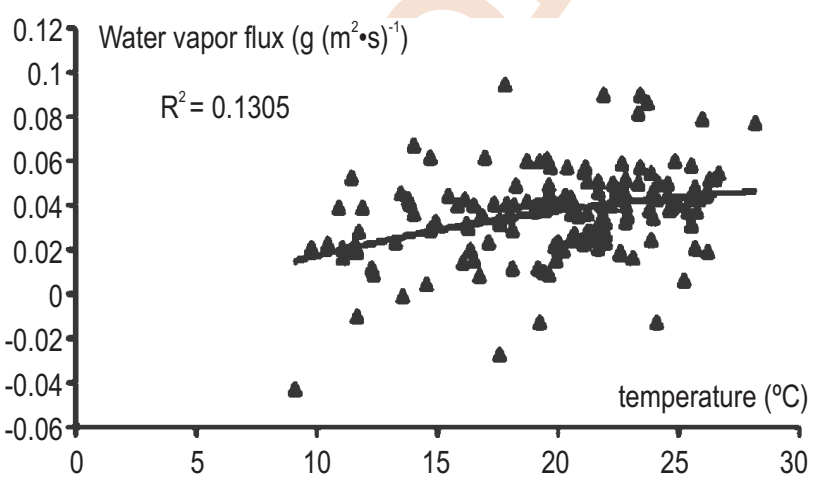

(a) growing season
Fig. 8: Relationship between water vapor flux and air temperature under different conditions. 


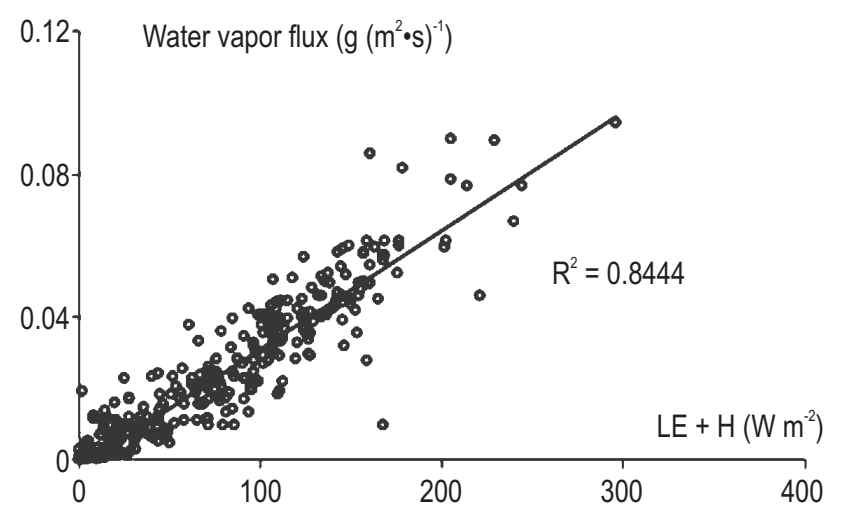

Fig. 9: Relationship between water vapor flux and radiation.

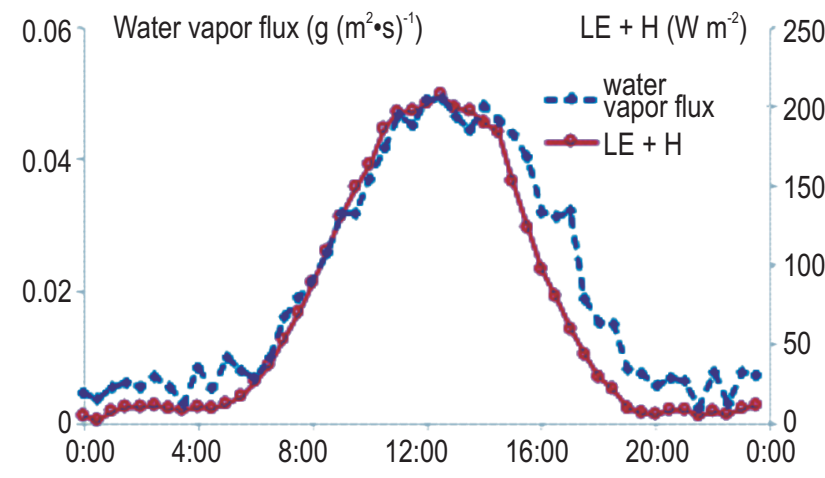

(a) Full Day

Fig. 10 : Diurnal variation of water vapor flux and radiation in sunny days.

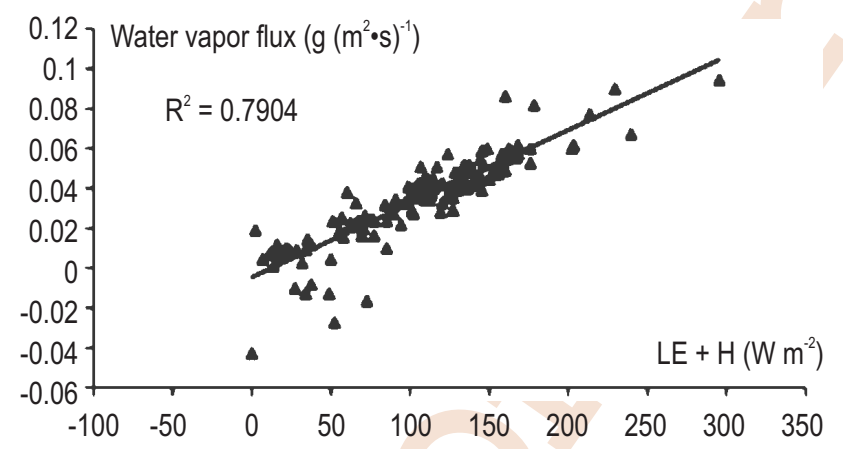

(a) rainfall

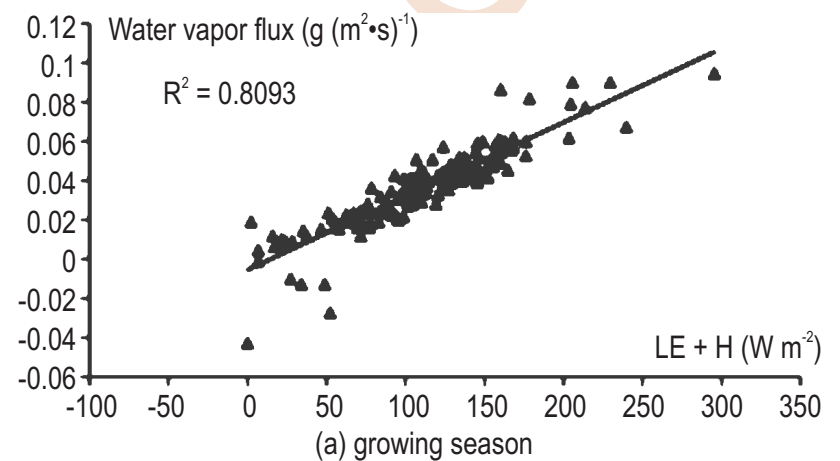

flux and radiation reached extremely high value at 11:30-13:30, but water vapor flux dropped sharply at 13:30. Studies have shown that strong solar radiation can cause stomatal closure of vegetation, resulting in midday depression of transpiration; stoma opens with the decrease of radiation in the afternoon, and vegetation transpiration recovers, thus transpiration increases. But since radiation is reduced, vegetation transpiration is weaker than that of midday (Dong et al.,1994;Fei et al.,2005).

On daily scale, water vapor flux was unimodal distributed, reached peak value at 12:00-15:00; the mean water vapor flux during the whole year was $2.05 \times 10^{-2} \mathrm{~g} /\left(\mathrm{m}^{2} \mathrm{~s}\right)$; there was no rule in daily variation of water vapor flux due to precipitation. On a

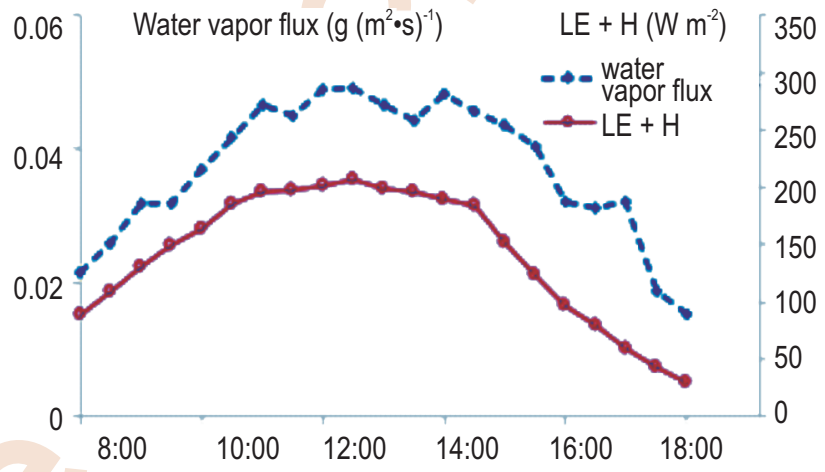

(b) Part time

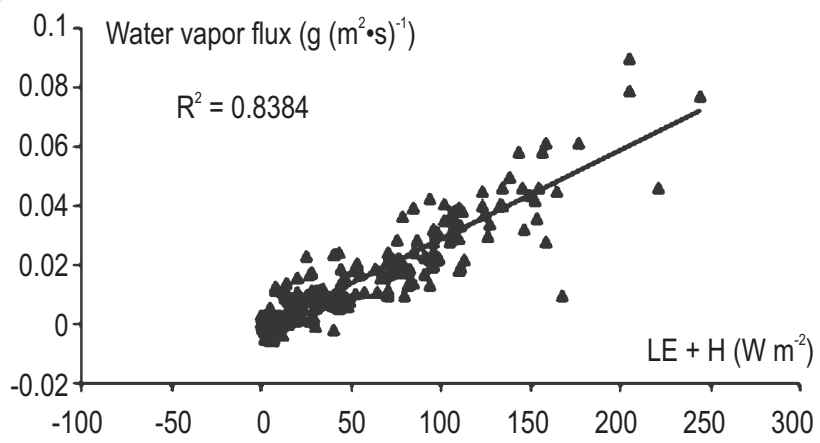

(b) non-rainfall

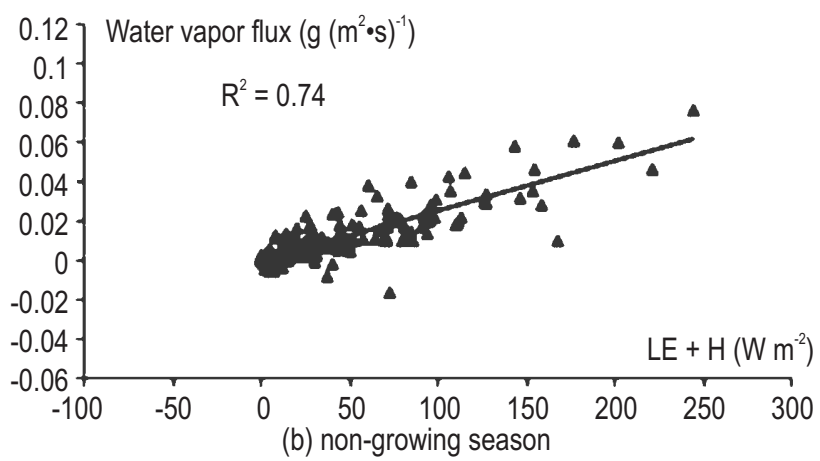

Fig. 11: Relationship between water vapor flux and radiation under different conditions. 
seasonal scale, the highest value in summer and lowest in winter and the daily accumulated value of water vapor flux in the growing season was 2.83 times than the non-growing season. This showed that water vapor flux had significant response to changes of temperature, radiation and VPD (vapor pressure difference).

With the increase of VPD, water vapor flux first increased, then decreased, and the turning point appeared at $3 \mathrm{KPa}$; the water vapor flux was proportional to the temperature, and when temperature was above zero, water vapor flux increased rapidly; water vapor flux was in linear growth against radiation. According to linear correlation, the maximum correlation coefficient $R^{2}$ between water vapor flux and radiation was 0.8444 . Therefore, the main factor affecting water vapor flux of riverside wetland in cold regions was radiation.

Due to limited test time, only one-year water vapor flux, there must be have some contingency and uncertainty; moreover compared with the research area, or wetland along the Songhua River, the flux contribution area for Eddy Covariance observation was small in scale, so couldn't represent the average condition of underlying surface in a larger area.

\section{Acknowledgment}

The authors acknowledge the National Natural Science Foundation of People's Republic of China (51579101, 51709111, 51879106), the National Key Research and Development Program of China (2016YFC0401401), Major Research Plan of the National Natural Science Foundation of China (91547209), and the Outstanding Youth in Science and Technology Innovation Talents of Henan province (185100510014). The authors would like to express their sincere gratitude to the anonymous reviewers for their constructive comments and useful suggestions that helped us improve our paper.

\section{References}

Baldocchi, D., R. Valentini and S. Running: Strategies for measuring and modelling carbon dioxide and water vapour fluxes over terrestrial ecosystems. Glo. Cha. Biol., 2,159-168(1996).

Dhami, N.B., M. Kandel, S.B. Gurung and J. Shrestha: Agronomic performance and correlation analysis of finger millet genotypes (Elusine corocana L.). Malays. J. Sustain. Agric., 2, 16-18 (2018).

Dong, X.J., B.Z. Yang and K. Guo: An investigation on the water physioecological characteristics of some Psammophytes. Acta Phytoecol. Sinica, 18, 86-94(1994).

El-Aziz, S.H.A.: Soil capability and suitability assessment of Tushka Area, Egypt by using different programs (Asle, Microleis And Modified Storie Index). Malays. J. Sustain. Agric., 2, 09-15(2018).

Falge, E., D. Baldocchi and R. Olson: Gap filling strategies for long term energy flux data sets. Agri. For. Meteorol., 107, 71-77(2001).

Fei, Y.J. and M.J. Lei: Correlation between ecological factors and transpiration intensity of Taxus chinensis var mairei. J. Henan Univ. Sci. Technol. (Natural Science), 26, 62-64 (2005).

Goulden, M.L., M. Litvak and S.D. Miller: Factors that control Typha marsh evapotranspiration. Aqu. Bot., 86,97-106 (2007).

Howlader, M.H.K., M.N. Islam, S. Biswas, M.E. Uddin, A. Shila, M.Z. Haque and N. Mahmud: Salt tolerance of chili genotypes during germination and seedling growth. Malays. J. Halal Res., 1, 01-07 (2018).

Irmak, S.: Dynamics of nocturnal, daytime, and sum-of-hourly evapo transpiration and other surface energy fluxes over nonstressed maize canopy. J. Irri. Drain. Engg.,137, 475-490 (2011).

Khan, M.M.H.: Occurrence, distribution, host preference and damage severity of red pumpkin beetle - a review. Malays. J. Halal Res., 1, 03-09 (2018).

Khattak, A.M., S. Abdullah and Z.A. Khattak: A study on some fundamental characteristics of sequences of soft real numbeers. Acta Sci. Malays., 2, 08-13(2018).

Li, J., Y.F. Liu and X.G. Yang: Studies on water-vapor flux characteristic and the relationship with environmental factors over a planted coniferous forest in Qianyanzhou Station. Acta EcologicaSinica, 26, 2449-2456(2006).

Lin, C., Z.G. Li and Q.Y. Liang: Preliminary research on Algae from Golden Bay Wetland in Heilongjiang Province. Nat. Sci. J. Har. Nor. Univ., 31, 92-96 (2015).

Madugundu, R., K.A. Al-Gaadi and E. Tola: Seasonal dynamics of surface energy fluxes over a center-pivot irrigated cropland in SaudiArabia. J. Environ. Biol., 38, 743-751(2017).

Meiresonne, L., D.A. Sampson and A.S. Kowalski: Water flux estimates from a Belgian Scots pine stand: A comparison of different approaches. J. Hydrol., 270, 230-252 (2003).

Peng, F.J., J.W. Ge and Y.F. Li: Characteristics of water vapor flux and their ecological significance in the Peat Wetlands of Dajiuhu,Shennongjia. Saf. Environ. Engg., 24, 1-8 (2017).

Shabi, T.H., A.K.M. Islam, A.K. Hasan, A.S. Juraimi and M.P. Anwar: Differential weed suppression ability in selected wheat varieties of Bangladesh. Acta Sci. Malays., 2, 01-07(2018).

Shukla, J. and Y. Mintz: Influence of land-surface evapotranspiration on the Earth's climate. Science, 215,1498-501(1982).

Shu, H.Y., H. Jing and X.F. Chen: Variation characteristics of water vapor flux in Anji Phyllostachys edulis forest ecosystem. Chin. J. Ecol., 35, 1154-1161 (2016).

Sun, L. and C.C. Song: Studies of the energy balance and evapotranspiration over the typical marsh wetland in Sanjiang plain. Adv. Water Sci., 19, 43-48(2008).

Wang, W.Z.: Characteristics of heat flux in a Chinese Fir plantations ecosystem in Huitong County. Cen. Sou. Univer. For. Technol., 30, 12-15 (2011).

Xu, Z.W., S.M. Liu and T.R. Xu: Comparison of the gap filling methods of evapotranspiration measured by Eddy Covariance System. Advan. Earth Sci., 24, 372-382 (2009).

Yong, J., Z. Jie and Z. Liwei: Analysis of heavy metals in the surface sediments of shallow lakes in Nanjishan (Poyang Lake) Natural Wetland in China. J. Environ. Biol., 38, 561-570 (2017).

Zhang, X.J., Z.X. Wu and C. Yang: Water vapor flux exchange and its environmental factors in a Tropical Rubber Plantation Ecosystem in Hainan Island. Chin. J. Trop. Cro., 36, 1432-1439(2015). 